Prosiding Seminar Nasional Teknologi Informasi dan Kedirgantaraan : Transformasi Teknologi untuk Mendukung Ketahanan Nasional, Yogyakarta, 13 Desember 2018

SENATIK 2018, Vol. IV, ISBN 978-602-52742-0-6

DOI: http://dx.doi.org/10.28989/senatik.v4i0.226

\title{
ANALYSIS OF THE EFFECT OF LINEAR AND NON LINEAR LOADS ON THE EFFECTIVENESS OF SINGLE PHASE TRANSFORMERS \\ Bambang Sudibya ${ }^{1}$, Mardiana Irawaty ${ }^{2)}$ \\ ${ }^{1}$ Program Studi Teknik Elektro \\ ${ }^{2}$ Program Studi Informatika \\ Sekolah Tinggi Teknologi Adisutjipto \\ Jl. Janti, Blok R, Lanud Adisutjipto Yogyakarta \\ Email: sudibya.stta@gmail.com
}

\begin{abstract}
Lately, PLN as the state electricity company that supply most of the electricity needs in Indonesia is being hit by a "trial" which is in a row with the burning of several Interbus Transformers (IBT) in several regions. This can be caused by the rupture of the bushing so that it triggers a short circuit and results in the burning of the transformer. However, so far the investigation of other causes has been minimal as well as the effect of the load which is primarily a nonlinear load. Electricity is a device / device that can function if it is electrified. The device / tool is used to convert electrical energy into other energy such as motion, heat, light and so on. Electricity load consists of linear load and non-linear load. changes in the use of linear loads to non-linear loads, among others, from incandescent lamps to TL lamps, and many non-linear loads that are widely used such as the use of induction motors (motors used in water pumps, refrigerators, air conditioners, etc.), rectifiers, static power converter (rectifiers and or inverters), electronic ballasts cause harmonics. Harmonics are sinusoidal waves with frequencies which are round multiples of the fundamental frequency. Harmonics can affect the work function of the transformer, which causes more heating to the iron core, which causes an increase in loss. In this study, the losses will be tested if the load is linear and also if it is loaded with non-linear loads. The results showed that for small loads, the response of the two loads showed almost the same current. While for moderate loads there is a difference that has not been so large, and for large loads large currents indicated there are large differences. Due to that reason, the copper losses and iron losses are greater when the load is large. Given copper losses there is a current flowing in the transformer winding and the presence of resistance in the winding (I2R1 + I2R2). It causes the increase in load current will increase copper losses. So thereby increasing copper losses causes a decrease in transformer efficiency.
\end{abstract}

\section{Keywords: linear, non-linear, losses, efficiency}

\section{Pendahuluan}

Sebagaimana kita ketahui transformator merupakan peralatan yang sangat penting untuk keberlangsungan penyaluaran energi listrik, juga sebagai sumber dari pada peralatanperalatan elektronik yang semuanya memerlukan transformator. Sebegitu pentingnya transformator ini, maka upaya untuk meneliti pnyebab terjadinya kurang optimalnya pengoperasian transformator dan juga peralatan lain seperti Miniatur Circuit Breaker (MCB) yang bisa Off pada saat bekerja pada batas normalnya (pada kemampuan daya) dari transformator maupun Miniature Circuit Braker $(M C B)$, banyak konsumen yang kurang menyadari bahwa ketidak optimalan peralatan peralatan tersebut dapat disebabkan oleh pembebanan yang pada perioda belakangan ini beraleh dari beban linier ke beban non linier. 
Trus apa sebenarnya beban linier dan beban non linier itu, beban linier adalah beban yang impedansinya selalu konstan sehingga arus selalu berbanding lurus dengan tegangan setiap waktu [3]. Beban linear ini mematuhi Hukum Ohm yang menyatakan bahwa arus berbanding lurus dengan tegangan. Gelombang arus yang dihasilkan oleh beban linear akan sama dengan bentuk gelombang tegangan. Apabila diberi tegangan sinusoidal, maka arus yang mengalir ke beban linear juga merupakan sinusoidal sehingga tidak terjadi distorsi dan tidak menimbulkan harmonisa. Beban ini berupa elemen pasif seperti resistor, computer dan kapasitor. Beberapa contoh beban linear adalah lampu pijar, pemanas, resistor,dan lain-lain. Sementara beban non linier adalah beban yang impedansinya tidak konstan dalam setiap periode tegangan masukan. Dengan impedansinya yang tidak konstan, maka arus yang dihasilkan tidaklah berbanding lurus dengan tegangan yang diberikan, sehingga beban non linear tidaklah mematuhi Hukum Ohm yang menyatakan arus berbandinglurus dengan tegangan [3].Gelombang arus yang dihasilkan oleh beban nonlinear tidak sama dengan bentuk gelombang tegangan sehingga terjadi cacat ( distorsi).

Dengan meluasnya pemakaian beban non-linear, gelombang sinusoidal ini dapat mengalami distorsi. antara lain dari lampu pijar ke lampu TL, dan bayaknya beban Non linier yang banyak digunakan seperti pemakaian motor induksi (motor-motor yang dipakai pada pompa air, kulkas, air conditioner, dll), penyearah, static power converter (rectifiers atau inverters), ballast elektronik menyebabkan timbulnya harmonisa. Harmonisa merupakan gelombang sinusoidal dengan frekuensi yang merupakan kelipatan bulat dari frekuensi fundamentalnya.

Suatu penelitian mengenai analisis pengaruh harmonisa terhadap kabel menyatakan bahwa dengan semakin berkembangnya peralatan elektronik dan bertambahnya alat elektronik yang dipakai maka semakin besar pengaruhnya ke sistem listrik [2]. Penelitian lain yang membahas analisis pengaruh harmonisa terhadap miniatur circuit breaker menghasilkan kesimpulan bahwa kebutuhan dalam pemanfaatan tenaga listrik di zaman moderen ini banyak mengalami perkembangan. Seiring dengan kemajuan teknologi, banyaknya penggunaan peralatan elektronik yang berakibat pada perubahan kinerja miniatur circuit breaker [3].

Beban linear adalah beban yang impedansinya selalu konstan sehingga arus selalu berbanding lurus dengan tegangan setiap waktu [3]. Beban linear ini mematuhi Hukum Ohm yang menyatakan bahwa arus berbanding lurus dengan tegangan. Gelombang arus yang dihasilkan oleh beban linear akan sama dengan bentuk gelombang tegangan. Apabila diberi tegangan sinusoidal, maka arus yang mengalir ke beban linear juga merupakan sinusoidal sehingga tidak terjadi distorsi dan tidak menimbulkan harmonisa. Beban ini berupa elemen pasif seperti resistor, induktor dan kapasitor. Beberapa contoh beban linear lainnya seperti: lampu pijar, pemanas, resistor,dan lain-lain. Gambar 1 berikut adalah contoh bentuk gelombang arus dan tegangandengan beban linear [3].

Tegangan / Arus



Gambar 1. Vektor diagram Tegangan dan Arus Beban Linier 
Beban non linear adalah beban yang impedansinya tidak konstan dalam setiap periode tegangan masukan. Dengan impedansinya yang tidak konstan, maka arus yang dihasilkan tidaklah berbanding lurus dengan tegangan yang diberikan, sehingga beban non linear tidaklah mematuhi Hukum Ohm yang menyatakan arus berbanding lurus dengan tegangan [3]. Gelombang arus yang dihasilkan oleh beban nonlinear tidak sama dengan bentuk gelombang tegangan dengan bentuk gelombang tegangan sehingga terjadi cacat (distorsi).

Dengan meluasnya pemakaian beban non linear, gelombang sinusoidal ini dapat mengalami distorsi. Gambar 2 berikut ini adalah beberapa contoh beban non linear untuk keperluan rumah tangga maupun industri seperti peralatan yang menggunakan busur api listrik, konverter elektronik, transformator balast magnetik, motor induksi, charger balast elektronik, dll. Kecendrungan penggunaan beban-beban elektronika dalam jumlah besar akan menimbulkan masalah yang tidak terelakkan sebelumnya. Berbeda dengan beban-beban listrik yang menarik arus sinusoidal (sebentuk dengan tegangan yang mensuplainya), bebanbeban elektronik menarik arus dengan bentuk nonsinusoidal walaupun disupalai oleh tegangan sinusoidal. Beban yang memiliki sifat ini disebut sebagai beban non linear

Beban non linear adalah peralatan yang menghasilkan gelombang-gelombang arus yang berbentuk sinusoidal berfrekuensi tinggi yang disebut dengan arusharmonisa. Arus harmonisa ini menimbulkan banyak implikasi pada peralatan sistemtenaga listrik. Misal rugirugi jaringan akan meningkat, pemanasan yang tinggi padakapasitor, transformator, dan pada mesin-mesin listrik yang berputar serta kesalahan pada pembacaan alat ukur RMS.

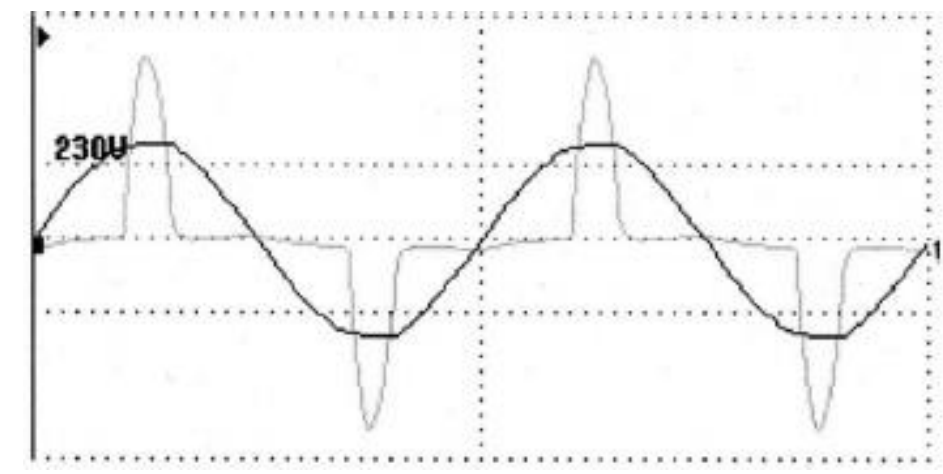

Gambar 2. Bentuk Gelomang Tegangan dan Arus Beban Non Linier

Transformator atau sering disingkat dengan istilah Trafo adalah suatu alat listrik yang dapat mengubah taraf suatu tegangan AC ke taraf yang lain. Maksud dari pengubahan taraf tersebut diantaranya seperti menurunkan Tegangan AC dari 220VAC ke 12 VAC ataupun menaikkan Tegangan dari 110VAC ke 220 VAC. Transformator atau Trafo ini bekerja berdasarkan prinsip Induksi Elektromagnet dan hanya dapat bekerja pada tegangan yang berarus bolak balik (AC).Transformator (Trafo) memegang peranan yang sangat penting dalam pendistribusian tenaga listrik. Transformator menaikan listrik yang berasal dari pembangkit listrik PLN hingga ratusan kilo Volt untuk di distribusikan, dan kemudian Transformator lainnya menurunkan tegangan listrik tersebut ke tegangan yang diperlukan oleh setiap rumah tangga maupun perkantoran yang pada umumnya menggunakan Tegangan AC 220Volt. Bentuk dan simbol transformator dapat dilihat pada gambar 3. 



Gambar 3. Bentuk dan Simbol Transformator (Trafo)

Sebuah Transformator yang sederhana pada dasarnya terdiri dari 2 lilitan atau kumparan kawat yang terisolasi yaitu kumparan primer dan kumparan sekunder. Pada kebanyakan Transformator, kumparan kawat terisolasi ini dililitkan pada sebuah besi yang dinamakan dengan Inti Besi (Core). Ketika kumparan primer dialiri arus AC (bolak-balik) maka akan menimbulkan medan magnet atau fluks magnetik disekitarnya. Kekuatan Medan magnet (densitas Fluks Magnet) tersebut dipengaruhi oleh besarnya arus listrik yang dialirinya. Semakin besar arus listriknya semakin besar pula medan magnetnya. Fluktuasi medan magnet yang terjadi di sekitar kumparan pertama (primer) akan menginduksi GGL (Gaya Gerak Listrik) dalam kumparan kedua (sekunder) dan akan terjadi pelimpahan daya dari kumparan primer ke kumparan sekunder. Dengan demikian, terjadilah pengubahan taraf tegangan listrik baik dari tegangan rendah menjadi tegangan yang lebih tinggi maupun dari tegangan tinggi menjadi tegangan yang rendah.

\section{Hasil dan Pembahasan}

Pengujian pada penelitian ini menggunakan sebuah transformator dengan data sebagai berikut: 1 buahTransformator dengan daya $500 \mathrm{VA}, 220 / 12$, a $=18.9, \mathrm{R}_{1}=0.15 \Omega$ dan $\mathrm{R}_{2}=0.009 \Omega$. Hasil pengujian beban linier dapat dilihat pada tabel 1 dan pengujian dengan beban non-linier dapat dilihat pada tabel 2 .

Tabel 1.Hasil pengujian dengan beban linier, tegangan kerja 220 Volt

\begin{tabular}{|l|c|c|c|c|}
\hline No. & $\begin{array}{c}\text { Beban } \\
(\mathrm{W})\end{array}$ & $\begin{array}{c}\text { Arus Beban } \\
(\mathrm{m} . \text { Amper })\end{array}$ & $\begin{array}{c}\text { Daya Beban } \\
\text { (VA) }\end{array}$ & $\begin{array}{c}\text { Rugi rugi Daya } \\
\text { (W) }\end{array}$ \\
\hline 1 & 40 & 185 & 40,7 & 0,00168 \\
\hline 2 & 60 & 277 & 60,94 & 0,002508 \\
\hline 3 & 100 & 459 & 100,98 & 0,004146 \\
\hline 4 & 150 & 685 & 150,7 & 0,00618 \\
\hline 5 & 200 & 908 & 199,76 & 0,008187 \\
\hline 6 & 250 & 1140 & 250,8 & 0,010275 \\
\hline 7 & 300 & 1375 & 302,5 & 0,01239 \\
\hline 8 & 350 & 1596 & 351,12 & 0,014379 \\
\hline 9 & 400 & 1825 & 401,5 & 0,01644 \\
\hline 10 & 500 & 2280 & 501,6 & 0,020535 \\
\hline
\end{tabular}


Tabel 2. Hasil pengujian dengan beban non linier, tegangan kerja 220 Volt

\begin{tabular}{|l|c|c|c|c|}
\hline No. & $\begin{array}{c}\text { Beban } \\
(\mathrm{W})\end{array}$ & $\begin{array}{c}\text { Arus Beban } \\
\text { ( Amper })\end{array}$ & $\begin{array}{c}\text { Daya Beban } \\
\text { (W) }\end{array}$ & $\begin{array}{c}\text { Rugi rugi Daya } \\
\text { (W) }\end{array}$ \\
\hline 1 & 40 & 185 & 40,7 & 0,185 \\
\hline 2 & 60 & 277 & 60,94 & 0,277 \\
\hline 3 & 100 & 459 & 100,98 & 0,459 \\
\hline 4 & 150 & 685 & 150,7 & 0,685 \\
\hline 5 & 200 & 1205 & 265,1 & 0,908 \\
\hline 6 & 250 & 1865 & 410,3 & 1,14 \\
\hline 7 & 300 & 2258 & 496,76 & 1,375 \\
\hline 8 & 350 & 2845 & 625,9 & 1,596 \\
\hline 9 & 400 & 4525 & 995,5 & 1,825 \\
\hline 10 & 500 & 8275 & 1820,5 & 2,28 \\
\hline
\end{tabular}

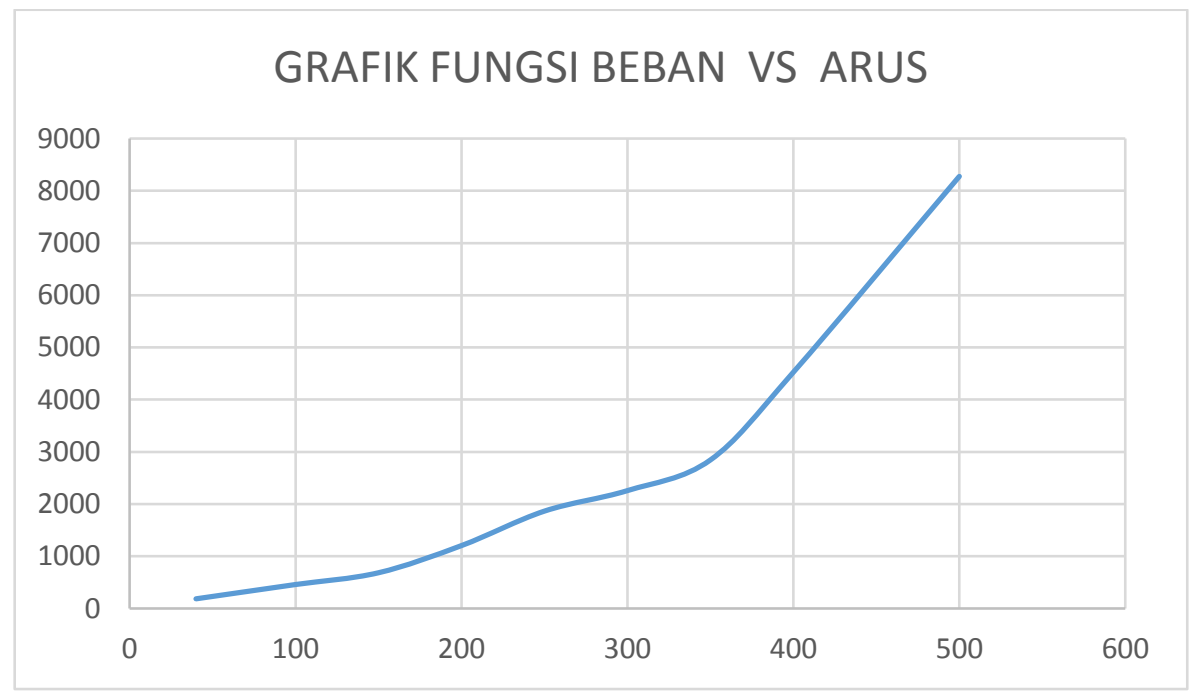

Gambar 4. Grafik hubungan antara beban non linier dengan arus output

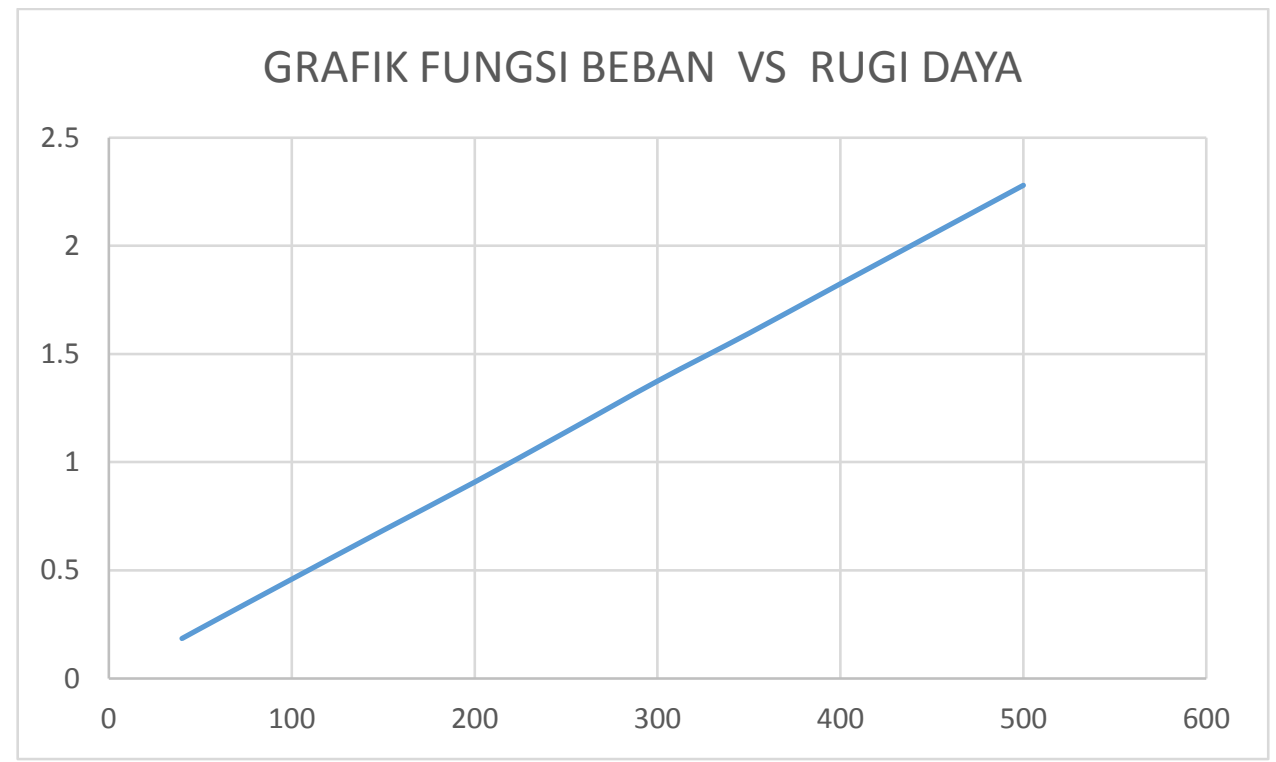

Gambar 5. Grafik hubungan antara Beban non linier dengan rugi daya 
Tabel 3. Pengaruh beban terhadap efisiensi

\begin{tabular}{|l|c|c|c|c|}
\hline No. & $\begin{array}{c}\text { Beban } \\
(\mathrm{W})\end{array}$ & $\begin{array}{c}\text { Daya Beban } \\
\text { (VA) }\end{array}$ & $\begin{array}{c}\text { Rugi rugi } \\
\text { Daya (W) }\end{array}$ & Effisiensi \\
\hline 1 & 40 & 40,7 & 0,185 & 1,000 \\
\hline 2 & 60 & 60,94 & 0,277 & 0,999 \\
\hline 3 & 100 & 100,98 & 0,459 & 0,999 \\
\hline 4 & 150 & 150,7 & 0,685 & 0,998 \\
\hline 5 & 200 & 265,1 & 0,908 & 0,998 \\
\hline 6 & 250 & 410,3 & 1,14 & 0,997 \\
\hline 7 & 300 & 496,76 & 1,375 & 0,997 \\
\hline 8 & 350 & 625,9 & 1,596 & 0,996 \\
\hline 9 & 400 & 995,5 & 1,825 & 0,995 \\
\hline 10 & 500 & 1820,5 & 2,28 & 0,994 \\
\hline
\end{tabular}

Sebagaimana kita lihat bahwa tabel 1 dimana transformator kita bebani dengan beban linier, hasil menunjukkan bahwa kenaikan beban akan menaikkan arus secara linier, demikian juga rugi-rugi daya meningkat secara linier dengan demikian effiensinya juga akan turun secara linier namun masih kecil, masih dalam batas kewajaran sebab masih mendekati 100\%. Pada pembebanan non linier (tabel 2) pada beban yang masih kecil baik hasil/keluaran arus masih sama, sementara untuk beban yang besar keluaran arus dan rugi-rugi terlihat beda, dimana pada beban linier $500 \mathrm{~W}$ dan beban non linier juga $500 \mathrm{~W}$, keluaran arus sebesar $2275 \mathrm{~mA}$ dan $8275 \mathrm{~mA}$. Sementara rugi-rugi tembaganya menunjukkan 0,0205W dan 2,28 W. Hal ini menunjukkan terjadi peningkatan rugi daya yang signifikan. Sementara untuk effisiensi pada percobaan ini masih menunjukkan effisiensi yang cukup tinggi (masih di atas $98 \%$ ) baik pada pembebanan linier maupun non linier.

\section{Kesimpulan}

1. Pembebanan linier akan menghasil perubahan arus dan rugi-rugi daya yang sifatnya linier juga.

2. Sementara pada pembebanan non linier menunjukkan bahwa perubahan arus yang besar, demikian juga perubahan rugi-rugi daya menunjukkan perubahan yang besar sampai 4 kali lipat.

3. Effisiensi pada transformator ini, baik pada pembebanan linier maupun pembebanan non linier masih menunjukkan hasil yang baik yaitu mendekati $100 \%$. Ini disebabkan unsur rugi-rugi yang dimasukkan rugi-rugi tembaga saja.

\section{Daftar Pustaka}

[1] Ariefin, 9 Nopember 2008"Transformator" Universita Mercubuana, Jakarta

[2] E. Darmawan. (2016).“ Analisis Pengaruh Harmonisa Terhadap Kabel ", Univertas Muhammadiyah Jakarta.

[3] M. Ardito. (2016)."Analisis Pengaruh Harmonisa Terhadap Miniatur Circuit Breaker". Universitas Indonesia Jakarta.

[4] Markoni, 25 Januari 2016" Teknik Tenaga Listrik". Graha Ilmu. Yogyakarta.

[5] Sumanto, 20 Nopember 1998, "Mesin Arus Bolak-balik" Andi Offset, Kanisius, Yogyakarta

[6] Yudi Utomo Putra, 9 Mei 2013 “Perbaikan faktor daya” Megatrika UGM. 